\title{
BioéthiqueOnline
}

\section{Engaging Ethical Issues Associated with Research and Public Health Interventions During Humanitarian Crises: Review of a Dialogic Workshop}

\author{
Anushree Dave, Julie Cumin, Ryoa Chung et Matthew Hunt
}

Volume 5, 2016

URI : https://id.erudit.org/iderudit/1044260ar

DOI : https://doi.org/10.7202/1044260ar

Aller au sommaire du numéro

Éditeur(s)

BioéthiqueOnline

ISSN

1923-2799 (numérique)

Découvrir la revue

Citer ce compte rendu

Dave, A., Cumin, J., Chung, R. \& Hunt, M. (2016). Compte rendu de [Engaging Ethical Issues Associated with Research and Public Health Interventions During Humanitarian Crises: Review of a Dialogic Workshop]

BioéthiqueOnline, 5. https://doi.org/10.7202/1044260ar
Résumé de l'article

Le 7 novembre 2014, l'atelier intitulé Humanitarian Health Ethics Workshop a été tenu à l'Université McGill, à Montréal. Hébergé conjointement par le Consortium de recherche sur l'équité en santé de Montréal et le Humanitarian Health Ethics Network, l'événement comprenait six présentations et une discussion extensive entre les participants, incluant des chercheurs du Canada, de Haïti, de l'Inde, de la Suisse et des États-Unis. Les participants étaient de diverses disciplines, soit l'anthropologie, la bioéthique, la médecine, l'ergothérapie, la philosophie, la physiothérapie, les sciences politiques, l'administration et la santé publique. L’objectif de l'atelier était de créer un forum de discussion entre experts et praticiens qui s'intéressent à l'éthique dans la prestation de soins de santé, en recherche et dans les interventions de santé publique en cours de crise humanitaire. Ce compte rendu résume les présentations, les thèmes clés qui ont émergé des discussions de la journée et identifie des pistes de recherches futures.
Droits d'auteur (C A Dave, J Cumin, R Chung et M Hunt, 2016

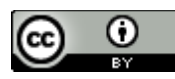

Ce document est protégé par la loi sur le droit d'auteur. L’utilisation des services d’Érudit (y compris la reproduction) est assujettie à sa politique d'utilisation que vous pouvez consulter en ligne. 


\title{
Engaging Ethical Issues Associated with Research and Public Health Interventions During Humanitarian Crises: Review of a Dialogic Workshop
}

\author{
COMPTE RENDU / REVIEW
}

Anushree Dave ${ }^{1}$, Julie Cumin ${ }^{2}$, Ryoa Chung ${ }^{3}$, Matthew Hunt ${ }^{4}$

Reçu/Received: 27 May 2015

Publié/Published: 18 Jan 2016

Éditrices/Editors: Lise Lévesque \& Cécile Bensimon

2016 A Dave, J Cumin, R Chung, M Hunt, Creative Commons Attribution 4.0 International License

\section{Résumé}

Le 7 novembre 2014, l'atelier intitulé Humanitarian Health Ethics Workshop a été tenu à l'Université McGill, à Montréal. Hébergé conjointement par le Consortium de recherche sur l'équité en santé de Montréal et le Humanitarian Health Ethics Network, l'événement comprenait six présentations et une discussion extensive entre les participants, incluant des chercheurs du Canada, de Haïti, de l'Inde, de la Suisse et des États-Unis. Les participants étaient de diverses disciplines, soit l'anthropologie, la bioéthique, la médecine, l'ergothérapie, la philosophie, la physiothérapie, les sciences politiques, l'administration et la santé publique. L'objectif de l'atelier était de créer un forum de discussion entre experts et praticiens qui s'intéressent à l'éthique dans la prestation de soins de santé, en recherche et dans les interventions de santé publique en cours de crise humanitaire. Ce compte rendu résume les présentations, les thèmes clés qui ont émergé des discussions de la journée et identifie des pistes de recherches futures.

\section{Mots clés}

éthique, dialogue interdisciplinaire, aide humanitaire, santé, atelier

\section{Summary}

On November 7th, 2014 the Humanitarian Health Ethics Workshop was held at McGill University, in Montreal. Cohosted by the Montreal Health Equity Research Consortium and the Humanitarian Health Ethics Network, the event included six presentations and extensive discussion amongst participants, including researchers from Canada, Haiti, India, Switzerland and the US. Participants had training in disciplines including anthropology, bioethics, medicine, occupational therapy, philosophy, physical therapy, political science, public administration and public health. The objective of the workshop was to create a forum for discussion amongst scholars and practitioners interested in the ethics of healthcare delivery, research and public health interventions during humanitarian crises. This review is a summary of the presentations given, key themes that emerged during the day's discussions, and avenues for future research that were identified.

\section{Keywords}

ethics, interdisciplinary dialog, humanitarian aid, health, workshop

\section{Affiliations des auteurs / Author Affiliations}

${ }^{1}$ Division of Experimental Medicine and Biomedical Ethics Unit, McGill University, Montreal, Canada

${ }^{2}$ Departments of History and Psychology, McGill University, Montreal, Canada

${ }^{3}$ Department of Philosophy, Université de Montréal, Montreal, Canada

${ }^{4}$ School of Physical and Occupational Therapy, and Centre for Interdisciplinary Research in Rehabilitation, McGill University, Montreal, Canada

\section{Correspondance / Correspondence}

Anushree Dave, anushree.dave@mail.mcgill.ca

\section{Remerciements}

Les auteurs sont reconnaissants à tous les présentateurs et aux participants de l'atelier pour la discussion stimulante. Les présentateurs ont révisé et corrigé les résumés de leurs présentations qui sont incluses dans ce rapport. Les auteurs remercient le Consortium de recherche sur l'équité en santé de Montréal qui a commandité l'événement (via le financement des Instituts de recherche en santé du Canada, ROH 115214 Recherche programmatique répondant à l'équité en santé).

\section{Conflit d'intérêts}

Aucun déclaré

\section{Acknowledgements}

The authors are grateful to all the presenters and workshop participants for the stimulating discussion. The presenters each reviewed and corrected the summary of their presentation that is included in this workshop report. The authors acknowledge sponsorship of the Montreal Health Equity Research Consortium (through funding from the Canadian Institutes of Health Research, ROH 115214 Programmatic Grant on Health Equity).

\section{Conflicts of Interest}

None declared 


\section{Introduction}

Humanitarian health ethics can broadly be defined as encompassing ethical dimensions of healthcare provision, health research and public health activities conducted during international responses to situations of humanitarian crisis such as war, disaster or epidemic disease outbreak. The Humanitarian Health Ethics Workshop [1] - which took place on November 7, 2014 at McGill University, in Montreal, Canada - aimed to encourage discussion amongst scholars and practitioners interested in the field of humanitarian health ethics. Sponsored by the Montreal Health Equity Research Consortium (through funding from the Canadian Institutes of Health Research) and cohosted by the Humanitarian Health Ethics Network, the event included six presentations and extensive discussion amongst participants. Participants were from Canada, Haiti, India, Switzerland and the US and had training in disciplines including anthropology, bioethics, medicine, occupational therapy, philosophy, physical therapy, political science, public administration and public health. This review has the following aims: a) to provide brief summaries of presentations delivered by Dr. Evelyne Durocher, Dr. Francois Audet, Dr. Jean-Hugues Henrys, Dr. Lisa Eckenwiler, Dr. Lisa Schwartz, and Dr. Philippe Calain, and the ensuing discussions amongst participants; b) highlight and discuss three key themes that emerged from the presentations: ethics of innovation, responsibilities of humanitarian practitioners and non-governmental organizations (NGOs), and vulnerability as a central consideration for humanitarian health ethics; and c) identify avenues for future research arising from the workshop.

\section{Methodological considerations}

The workshop was designed with the goal of creating an opportunity for sustained and substantial discussion amongst participants (researchers, practitioners and students). To this end, presenters were asked to limit their presentation to a maximum of 20 minutes in order to allow for significant discussion after each presentation. We also gave attention to the sequence of presentations in an effort to create a cumulative discussion across the sessions, rather than considering each topic in isolation. The number of participants was limited to 30 and the room was set up in a large rectangle in order to encourage exchange and dialogue. The final session of the workshop was an open discussion to consider the themes that had emerged across the presentations and the discussions that followed.

We elected to organize a bilingual workshop with presentations and discussion taking place in both English and French. The goal was to create an opportunity for exchange amongst both anglophone and francophone scholars, and to overcome some of the barriers for such exchange due to the dominance of English in many academic fora. However, not all of the participants were sufficiently comfortable in both languages to be able to follow all aspects of the discussion. This challenge was partially addressed as fellow participants offered simultaneous translation to others, as needed.

\section{Presentations}

\section{Vulnerability and equity in the international response to the $\mathbf{2 0 1 0}$ Haiti earthquake}

Evelyne Durocher presented findings of a study on perspectives of vulnerability following the 2010 Haiti Earthquake response. The project was based on semi-structured interviews with 14 Haitian and 10 expatriate participants who took part in the earthquake response as healthcare providers or decision-makers. Dr. Durocher introduced Rogers, Mackenzie, and Dodds' feminist framework [2] and applied this to the analysis of different sources and states of vulnerability. As reflected in the narratives of participants, sources of vulnerability may be inherent, meaning they are related to the corporeality of humans as well as human social dependence. There are also situational sources of vulnerability, contingent on particular conditions that render individuals more likely to incur harm. The third source of vulnerability is pathogenic, where inherent or situational vulnerability is made worse by a pernicious institutional, social or political context. States of vulnerability are dispositional, referring to individuals having the attributes that make them vulnerable to a particular harm, or occurrent, meaning the risk of harm is increased in a situation. 
This analysis provides a more nuanced understanding of vulnerability and how it is addressed in humanitarian response settings. Dr. Durocher pointed to the ways that context shapes vulnerability, citing an example in which disabled individuals were going to be evacuated in priority from a camp at risk of flooding. In this case, however, all those living in tents in the camp were experiencing high levels of vulnerability, though for some this was exacerbated by inherent physical characteristics. This example also served to illustrate how targeting specific groups in relief efforts, and thereby implicitly or explicitly prioritizing vulnerability, can result in the exclusion of other individuals, who are also experiencing vulnerability. Furthermore, definitions of vulnerability tended to be determined by "men in suits" (quoting participant) who had limited knowledge of the local socio-cultural landscape.

\section{Disparities in Ebola care provision}

Francois Audet examined ongoing disparities in Ebola care provision in West Africa, and referred to the failure of professional organizations to address the interplay between healthcare providers' duties to their patients and to themselves, their families, and others. Canadian nurses and doctors did not have access to proper safety equipment, and he suggested that infected nurses in Atlanta and Dallas had likely not taken proper protective measures due to a range of institutional and individual reasons. These steps should have been thoroughly outlined and implemented as per protocol in typical situations regarding such infectious diseases.

Dr. Audet discussed the relationship between very weak healthcare systems that rely on external support and the conditions under which Ebola has spread. Given the nature of the Ebola outbreak, these systems have been further undermined. He outlined external and internal factors that influence how NGOs have responded. External factors such as media pressure and appeals for donors often beg ethical questions of protecting the dignity and confidentiality of victims, while internal factors such as risk management with respect to health workers are also poorly regulated in crisis situations.

\section{L'épidémie de choléra et la Mission des Nations Unies pour la Stabilisation en Haïti: considérations éthiques}

Jean-Hugues Henrys drew on his experiences collaborating with the UN during the 2010 cholera outbreak in Haiti to develop a critical analysis of the roles and responsibilities of the UN and other international agencies. The presentation began with an overview of past UN interventions in Haiti, which represent half of all its operations in North and South America over the past 60 years. Dr. Henrys highlighted this extensive prior experience of the UN in Haiti, in order to then question what happened during the cholera outbreak in which 9,000 Haitians lost their lives.

Dr. Henrys described how UN troops dispatched to Haiti introduced a "South-Asian strain" of the cholera bacteria (as was admitted by Ban Ki-Moon months later) in the Artibonite river through poor sewer evacuation at their base. The rapid spread and deadly outcome of the disease characterize the first time the UN was associated with a health crisis of such magnitude. Dr. Henrys stressed tensions between the UN and Haitian government that are not captured by health figures. He discussed sources of conflict, including frustration and lack of communication. He also questioned the disjuncture between the treatment approaches taken by the UN and the community-based strategy preferred by the Haitian government.

\section{Real-time responsiveness and disaster research ethics}

Lisa Eckenwiler discussed the need for real-time responsiveness for the ethical oversight of disaster research. She mentioned that the current system of ethical review and monitoring of research is poorly adapted to the realities of conducting research in the context of an unfolding disaster, in part due to the need for rapid implementation of research in the days or weeks following the event. Innovative approaches are needed to ensure that sufficient ethical oversight is possible. Dr. Eckenwiler discussed the possibility of ongoing critical engagement by Research Ethics Committees (REC) in disaster research, considered the feasibility of a real-time approach to 
oversight, and addressed questions of how responsiveness to rapidly changing situations could be achieved. She also highlighted ethical considerations specific to disaster research that are not always apparent during REC review and approval. Thus, ongoing dialogue and ethical guidance is necessary.

One way in which this guidance can be addressed is through regular feedback via real-time exchanges of information that can have a rapid, direct, and ongoing influence on disaster research. It allows attentive researchers to be responsive, and adaptations of the protocol may be recommended by the REC. This process rests on a temporal factor, with real-time responsiveness extending throughout the project, and not just reserved to the initial phases of research design. Dr. Eckenwiler raised a number of possible objections to the real-time response approach and its perhaps idealistic nature: the boundaries of responsibility between the REC and the researcher remain vague, REC independence may be diminished if there is ongoing close contact with researchers, and the great variability in interpretation and practices might not be taken into consideration. She offered responses to these objections.

\section{Integrating procedural justice and normative statements for applied humanitarian ethics}

Dr. Lisa Schwartz discussed the sources of and gaps in ethical guidance for humanitarian workers and proposed that a combination of guiding statements and procedural ethics should be applied to help manage uncertainty. She outlined ethically challenging issues in disaster bioethics and discussed sources of guidance to address these issues, such as professional codes of ethics/conduct, and the Fundamental Humanitarian Principles of impartiality, neutrality, and independence. She argued that normative statements from professional organizations provide several advantages such as rapid problem solving, a 'shorthand' for guidance, and support when facing role conflicts. However, there are also limitations to the guidance they provide. Limitations include unclear application in many situations, broad scope, variation in how they are interpreted, lack of context, and lack of clarity in how to prioritize.

Dr. Schwartz proposed three ideas to help humanitarians respond to ethical uncertainty: 1) know relevant rules and responsibilities; 2) understand why they were written in a particular way; and 3) be able to critically apply the rules. She suggested resources that offer a process for analyzing ethical issues without predetermining substantive ethical commitments. For example, the Humanitarian Health Ethics Analysis Tool (HHEAT) provides a more transparent and systematic approach to ethical deliberation. Employing such a tool can satisfy rules of procedural justice; consistency lends a degree of predictability and fairness, bias suppression (neutrality), accuracy, correctability, representativeness, and ethicality. She ended by asking several questions about the origins of substantive ethics statements and how detailed ought ethical statements to be in order to promote high standards of action.

\section{Ethics and cartographies of disease}

Philippe Calain focused on ethical issues related to innovations in mapping populations during epidemics and highlighted concerns such as the accuracy of data and socio-cultural issues. He suggested that mapping disease can have positive, neutral or negative consequences depending on how the information is developed, stored and used. He pointed to issues of consent associated with photography and remote sensing, and that technology allows for images to be taken at great distance but that still might intrude on privacy. Mapping also has public health benefits, including demographic applications, and mapping of disease incidence and risks.

Dr. Calain presented multiple situations of mapping, especially in relation to the ongoing Ebola outbreak in West Africa where operational maps include contact tracing and areas deemed hostile to outsiders. These examples raise the question of whether or not geographical anonymity is possible. He suggested that since geographic information system (GIS) data is no different than other public health data, data collection should aim to respect confidentiality, while optimizing benefits and minimizing harm. 
Dr. Calain identified arguments against open GIS data sharing such as ownership of data, the contemporary ethos of science, and distribution of benefits and burdens. Arguments for sharing included reciprocity and solidarity. In contexts when seeking consent is not feasible, cartographers need to be aware of burdens and risks for individuals and communities, and to inform communities about the purpose, benefits, and risks of mapping. Map makers can also minimize risks by only collecting information that is necessary for a specific (humanitarian) objective, using non-identifying information when possible, limiting data fields, and implementing appropriate security measures to protect privacy.

\section{Themes}

\section{Innovation in humanitarian aid}

As innovations are introduced in humanitarian aid, there is often a lag with the development of consensus and guidelines about their ethical parameters. Considerations related to the "Ethics of Innovation" arose in multiple presentations during the workshop and were an important element of the discussion that occurred amongst the participants. Discussion following Dr. Calain's presentation honed in on the need for guidance related to the possibility of tracking and localizing people with new technologies, especially with the rise of mobile devices and geolocation. A key risk of epidemic mapping, as identified by Dr. Calain, lies in seeing people purely as vectors of disease, rather than as human beings. It was suggested that the use of technology may obscure some of these concerns, making humanitarians less vigilant about issues of confidentiality, for example, in relation to GIS data. Dr. Eckenwiler discussed the need for research in humanitarian crises to support innovative practices and learn from these experiences so they can be replicated. Research in humanitarian crises is a key vehicle for achieving these goals. However, she discussed the ways in which the current research review system is poorly adapted to disaster research, requiring innovations in the ways that research in disasters is reviewed and oversight is provided. These innovations also suggest a role for technology: real time responsiveness will require reliable communication links between RECs and researchers in disaster settings. Dr. Audet discussed Ebola treatment disparities, leading to a discussion of the development of new therapeutics and diagnostics. He discussed influences on the development of ZMapp and questions were raised about the ethics of privatization of research and development in the health sector, especially in relation to epidemic disease and other public health threats.

\section{Responsibilities of humanitarian practitioners and international organizations}

Workshop participants engaged in considerable discussion around the responsibilities of humanitarian health workers and researchers. A particular concern for humanitarian health researchers was if and when they should place advocacy ahead of their research objectives. Participants discussed this topic in relation to duties of humanitarian researchers, their roles, and individual safety, with opinions ranging from concern that advocacy might compromise rapport built with a local community, to researchers feeling obligated to forego research aims to advocate for justice when faced with situations that were oppressive. These considerations were highlighted during discussion following Dr. Eckenwiler's presentation on real-time responsiveness and disaster research ethics. As researchers identify sources of injustice or marginalization, the line between being a humanitarian researcher and humanitarian worker may become less clear, especially for researchers who are part of humanitarian organizations.

Issues of responsibility - especially of intergovernmental organizations and other international actors - were highlighted by discussions of the Haitian cholera outbreak and the West African Ebola outbreak. These situations reinforce the need for a robust model of accountability and justice related to the roles and implications of international actors. The Ebola case also highlights the duty of states and organizations towards humanitarian and local health workers, including for their protection. 


\section{Centrality of vulnerability for humanitarian health ethics}

The concept of vulnerability was a recurrent theme across the workshop presentations and discussions. The notion of how to understand vulnerability, how to protect and support those who are vulnerable, and the importance of mitigating sources of vulnerability, were all raised and examined. Questions surrounding the conceptualization of vulnerability were raised with regards to disasteraffected populations, healthcare providers, researchers and research participants. During the discussion, Dr. Durocher elaborated on the need to better conceptualize vulnerability, which is a term often mentioned in humanitarian aid but rarely clearly defined. The distinction between "dispositional" and "occurrent" states of vulnerability may be a helpful lens to examine the characteristics of those experiencing or at risk of developing a particular vulnerability. Contributors added that this was also a useful way to view the vulnerability of health workers, who are often put into dispositional states of inherent and situational vulnerability during humanitarian responses. Dr. Audet stressed that there was a need for more guidance in acute response settings to protect not only health practitioners, but also to uphold notions of equity which are too often ignored and may create rifts amongst expatriate responders, local workers, and the affected population. The impact of crises on local institutions and the implications for humanitarian aid were also debated, with Dr. Henrys pointing to crises such as the 2010 Haiti earthquake in which the already overstretched government had incurred considerable damage. This prompted reflection on how international agencies should address the needs of the population while also respecting national institutions. It was noted that NGOs can undermine government and societal structures and effort should be devoted to build local capacity and avoid circumventing local institutions.

\section{Future Avenues of Research}

Following a day of presentations and discussion linked by the three overarching themes presented above, several key questions remained unanswered, with participants suggesting these fields as potential avenues for further research:

1. What ethical guidance can best support the integration of new technologies in humanitarian action? With the rapid uptake of technological innovation in crisis settings, humanitarians will benefit from support in deciding when and how to implement these new developments.

2. How can models and procedures of accountability be improved, especially in relation to the responsibilities of inter- and non-governmental organizations?

3. How can duties to protect health workers from harm best be addressed in situations of epidemic disease, and who holds these responsibilities?

4. How can humanitarian health researchers anticipate and navigate situations in which they identify situations of injustice?

5. How can a more nuanced understanding of vulnerability be incorporated in the planning and implementation of humanitarian interventions?

\section{Conclusions}

The goal of the November 7, 2014 Humanitarian Health Ethics Workshop was to create the opportunity for sustained and substantial discussion amongst a diverse group of participants. This goal was largely achieved. An animated and engaging discussion took place regarding a wide range of ethical considerations associated with humanitarian healthcare, research and public health activities. The workshop also led to the identification of important topics for further research in the area of humanitarian health ethics. Several challenges were encountered, however, including the group size and the bilingual nature of the event, considerations that could be addressed in future events. The workshop was a valuable opportunity to encourage dialogue amongst an international, interdisciplinary group of researchers, students and practitioners on topics related to humanitarian health ethics. 


\section{References}

1. Hunt M., Schwartz L., Pringle J., Boulanger R., Nouvet E., O'Mathúna D. A Research Agenda for Humanitarian Health Ethics. PLOS Currents Disaster. 2014 Aug 12 . Edition 1. doi: 10.1371/currents.dis.8b3c24217d80f3975618fc9d9228a144.

2. Mackenzie C., Rogers W., and Dodds S., eds., Vulnerability: New Essays in Ethics and Feminist Philosophy; 2013. Oxford: Oxford University Press.

\section{Speaker Information}

Evelyne Durocher, $\mathrm{PhD}$, OT, is a post-doctoral fellow at the Western University School of Occupational Therapy

Francois Audet, $\mathrm{PhD}$, is a Professor at the Université du Quebec à Montreal and Scientific Director of the Canadian Institute for Humanitarian Crisis and Aid

Jean-Hugues Henrys, MD, is the Dean of the Faculty of Medicine and Health Sciences at the Université Notre Dame, Haiti

Lisa Eckenwiler, $\mathrm{PhD}$, is an Associate Professor at George Mason University in the Department of Philosophy and Health Administration Policy

Lisa Schwartz, PhD, is a Professor in the Department of Clinical Epidemiology and Biostatistics at McMaster University in Hamilton, Ontario

Philippe Calain, MD, PhD, is a researcher at the Unité de Recherche sur les Enjeux et Pratiques Humanitaires with Médecins sans frontières - Switzerland 